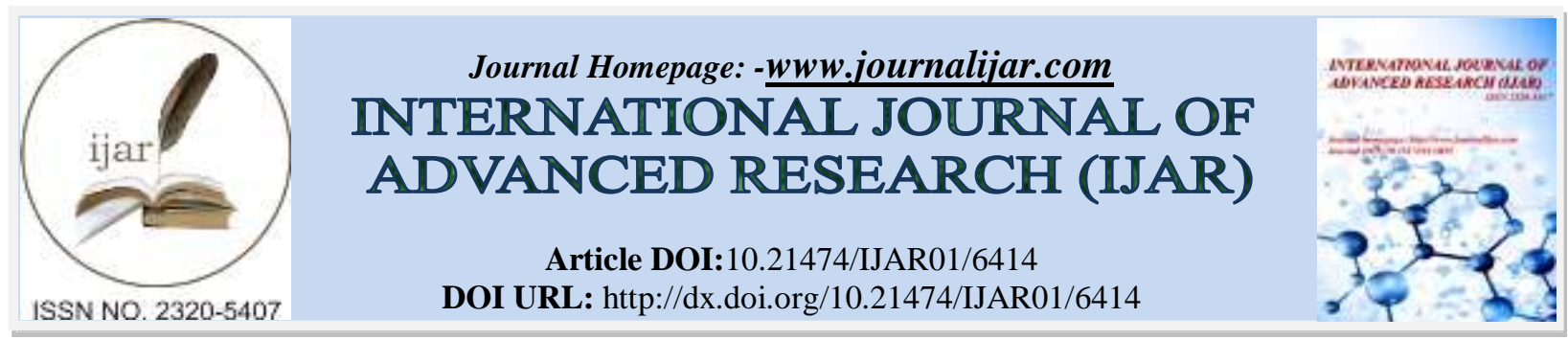

RESEARCH ARTICLE

\title{
PRODUCTION OF BIODIESEL FROM MICROALGAE.
}

\section{DivyaA $^{1}$, Gauri $\mathbf{H}^{1}$, Lokesh $\mathrm{A}^{\mathbf{1}}$, Suraj $\mathbf{H}^{\mathbf{1}}$, M.Mandke ${ }^{2}$ and ${ }^{\text {Preeti Zade }}$.}

1. Under graduate students in the Department of Instrumentation Engineering.

2. Professor, Department of Chemical Engineering.

3. Professor in Chemistry, Department of Applied Science. BharatiVidyapeeth College of Engineering, Navi Mumbai, INDIA.

\section{Manuscript Info}

\section{Manuscript History}

Received: 02 December 2017

Final Accepted: 04 January 2018

Published: February 2018

Key words:-

Biodiesel, Cladophoragoensis, microalgae, biofuels,

transestrification.

\begin{abstract}
Biodiesel has gained much attention in recent years due to its ecofriendly nature, non-toxic characteristics, biodegradability and lower net carbon cycle compared to conventional diesel fuels. In the current study, potential algal specie Cladophoragoensis ${ }^{1}$ were collected from creaks of Navi Mumbai and employed as a feedstock for biodiesel production. Present review focuses on algal biofuels and their environmental sustainability. Microalgae are autotrophic microorganisms having extremely high photosynthetic efficiency and are valued as rich source of lipids, hydrocarbons, and other complex oils for biodiesel. This extracted oil was converted into biodiesel via transestrification process.
\end{abstract}

Copy Right, IJAR, 2018,. All rights reserved.

\section{Introduction:-}

Energy security is a serious concern for a sustainable economy where it has necessitated alternative renewable energy that can have the potential to meet the futuristic needs. ${ }^{2}$ Among renewable energies, carbon neutral biofuels from microalgae appear to be a promising move towards sustainability and cleaner fuels owing to its attributes of high $\mathrm{CO}_{2}$-sequestering capability ${ }^{3}$, high lipid productivity and being easily cultivable in an open pond and waste/marine/brackish water.

Microalgae are autotrophic microorganisms having extremely high photosynthetic efficiency and are valued as rich source of lipids, hydrocarbons, and other complex oils for biodiesel besides being an invaluable source of bioethanol, bio methane, and bio hydrogen. Biodiesel produced from oilseed crops such as jatropha and soy have lower yields per unit land area and threaten food security. ${ }^{4}$ Indeed, microalgae have higher oil yields amounting to about 40 times more oil per unit area of land in comparison to terrestrial oilseed crops such as soy and canola. Further, microalgae production does not require arable land for cultivation. Research and developments in the field of new materials and advanced designs for cultivation in closed bioreactors, use of waste water for biomass production, screening of efficient strains, high-value co product strategy, and cutting-edge metabolic engineering are thought to provide the biggest opportunities to substantially improve the cost effectiveness of such production systems. $^{5-6}$ In the light of aforesaid issues, algae are becoming the centre of attention as an optional renewable source of biomass for production of bioethanol, which is grouped under Third generation biofuels. Extensive research is being carried out over the last three decades there has been extensive research on algal biofuels production and the use of algae for $\mathrm{CO}_{2}$ bioremediation. 
Hence Algae have proved itself as one of the most efficient resources when it comes to renewable raw material for biofuels. ${ }^{7}$ The vegetable oil from algae can be harvested directly (by the esterification process) or it can be refined into a variety of biofuels, which include renewable diesel and jet fuel. The extracted carbohydrates from algae can be fermented to make additional biofuels, including ethanol and butanol ${ }^{8}$, as well as other products such as plastics and biochemical. Microalgal biomass can be used for pyrolysis oil or combined heat and power generation. Renewable diesels derived from microalgae and jet fuels can directly replace petroleum fuels without modification of engines. Algae can be considered a biomass resource which is without carbon footprint. Even if there are different technologies described in greater detail, this is considered as the principal energy process for aquatic biomass. Due to their rich photosynthetic activity and efficacy to generate lipids, a biodiesel feedstock, microalgae have engrossed the attention of various researches.

The main objective of this work is to develop a novel integrated experimental and computational approach, utilizing a microalgal strain grown at bench-scale, with the aim to systematically identify the conditions that optimize growth and lipid production, in order to ultimately develop a cost-effective process to improve the system economic viability and overall sustainability. Integrating cultivation with wastewater treatment improves the economics of microalgal based biofuel production and allows for the sustainable reuse of nitrogen (N) and phosphorus (P) from waste streams.

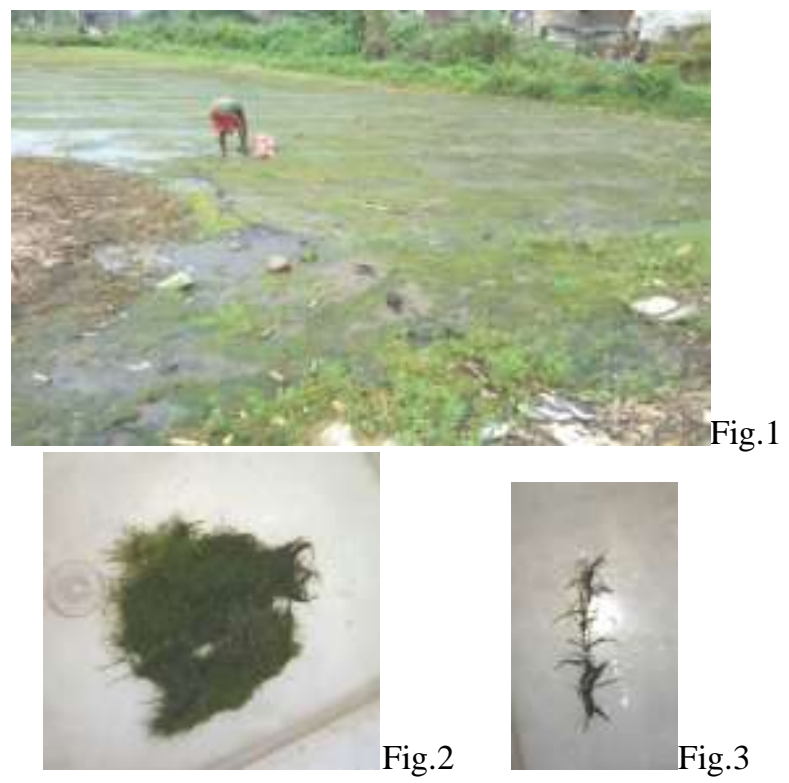

Cladophoragoensis is the most common green algae, available abundantly in springs, ponds and brackish water. The cell wall is composed of two layers, the inner one is made up of cellulose, and the outer is purely pectose by nature. It produces lipids, carbohydrate and proteins that can be utilized for the production of biodiesel, or bioethanol. In this study, potential algal strains of Cladophoragoensis were used for the production of biodiesel. The effect of solvent to oil ratio, size of algal biomass and time was studied on the percentage yield of oil extracted. While in transestrification reaction the effect of molar ratio, temperature, reaction time and amount of catalyst (Sodium Hydroxide) was studied on the amount of biodiesel produced.

\section{Materials:-}

All the techniques and protocols used in the proposed study were standardized according to the literature available.

\section{Methodology:-}

Collection and pretreatment of algae specie: The algae samples were collected from a nearby creek in Kharghar, Navi Mumbai. The samples were spread under sun in an open area for 48 hours to evaporate the amount of water associated with biomass. The dried samples were grinded, and the fine powder was passed through a 500 micron sieve, to remove the oversize particles. This step is necessary, to get smaller size particles which will have a physical contact with the solvent used for extraction. 


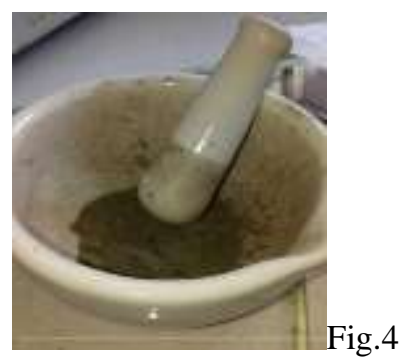

Oil Extraction: 20 gram of grinded algal biomass was treated with $20 \mathrm{ml}$ of solvent. Solvents n-Hexane and Diethyl Ether were used for the extraction of oil from algal biomass. The mixture was kept at room temperature for 24 hours. A layer of oil on the solvent surface was formed, which was separated from the residue. We obtained a higher fraction of oil extracted by suing the combination of both the solvents.

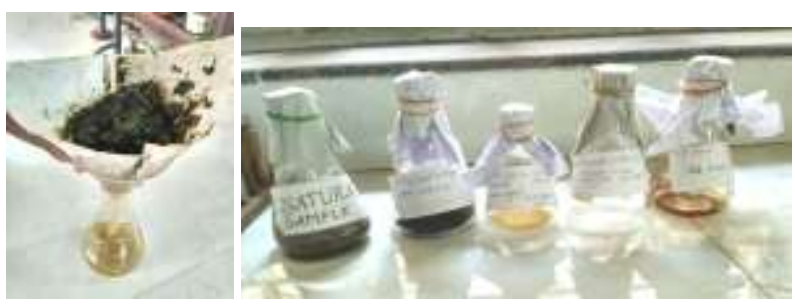

Fig.5

Fig.6

Biomass Collection: The Biomass was collected after filtration and weighted.

Evaporation: The extracted oil was separated by evaporating the solvent in a rotary evaporator (cryogenic distillation). Initially, the evaporator was kept at $34{ }^{\circ} \mathrm{C}$ for 15 minutes to evaporate Di-ethyl Ether. Temperature was then raised to $69{ }^{\circ} \mathrm{C}$ to remove n-hexane. This process left behind solvent free oil in the evaporation flask.

Transesterification: The extracted oil was converted to biodiesel through transesterification reaction in the presence of methanol. In this process triglycerides react with the alcohol to form the fatty acid ester (biodiesel) and the glycerol. The mixture of catalyst and Methanol was poured into the algal oil in a conical flask the following reaction was followed.

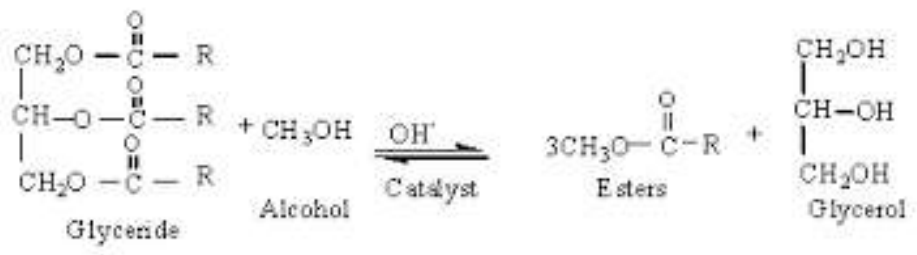

$0.25 \mathrm{gm} \mathrm{NaOH}$ was mixed with $24 \mathrm{ml}$ Methanol and stirred properly for 10 minutes. During this reaction the algal oil was allowed to react with the methanol in the presence of alkali due to larger surface area of smaller algal specie. The smaller sized particles have a good interaction with solvent as compared to large particles and thus enhance the yield.

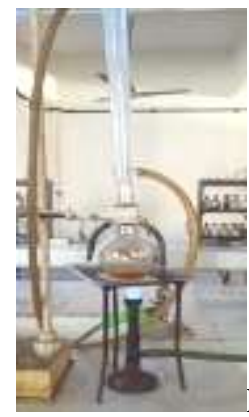

Fig.7

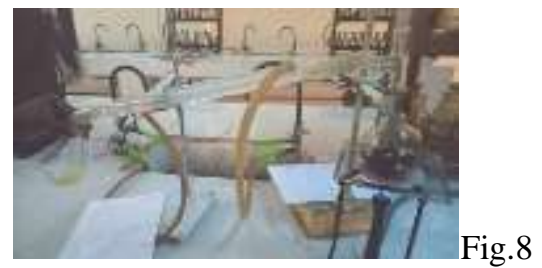


Settling: After shaking the solution was kept for 24 hours to settle the biofuel and sediment layer clearly.

Separation of Biofuel: The biofuel was separated from sedimentation by flask separator carefully. Quantity sediment (Glycerine, pigments, etc.) was measured.

Washing: Biofuel was washed by $5 \%$ water until it become clean.

Drying: Biofuel was dried by using dryer and finally kept under running fan for 12 hours.

Storage: Biofuel production was measured by using measuring cylinder; $\mathrm{pH}$ was measured and stored for analysis.

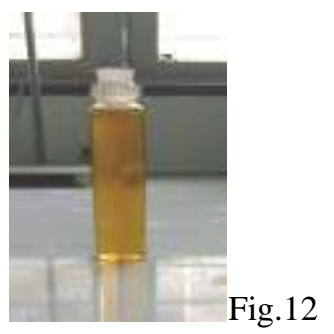

\section{Result:-}

Effect of temperature: Reaction temperature also affects the amount of biodiesel production. The temperature was varied from 80 to $100^{\circ} \mathrm{C}$. Reaction is carried out near the boiling point of methanol under atmospheric conditions. It was observed that higher temperature favors the biodiesel production. ${ }^{12-13}$

Effect of catalyst amount: The role of catalyst in transesterification reaction is very important. Transesterification reaction can be carried out with both acidic or alkali catalyst. However, using acidic catalyst has the disadvantage due to its corrosive nature as compared to the alkali catalyst. Sodium hydroxide was used as a catalyst, with amount ranging from 0.3 to $0.5 \%$ of weight of oil. Presence of catalyst has increased the rate of reaction and hence the yield was increased.
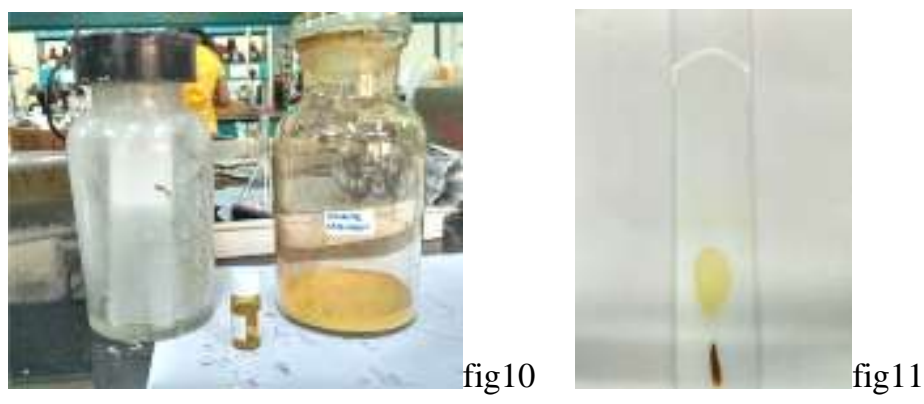

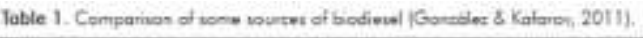

\begin{tabular}{|c|c|c|c|c|c|c|c|}
\hline ton & 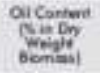 & 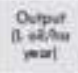 & In' land Uned & 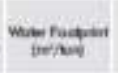 & Modetion: & Nortor & $\begin{array}{l}\text { Euter } \\
\text { ratis }\end{array}$ \\
\hline Seqtesm. & 18 & 635 & 18 & 4200 & $0.40-0.00$ & 0.2 & 00 \\
\hline kenenod & A1 & 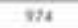 & iz & 4390 & a96 & 20 & v2 \\
\hline Sulpory & 40 & 1003 & $n$ & 4000 & 0.82 & 0.1. & 90 \\
\hline ardm & 36 & 2365 & 2 & $\$ 000$ & 9.68 & bi & 35 \\
\hline Gater & Al & $130 \%$ & 8 & 24700 & $0.92-1.56$ & $\omega$ & 89 \\
\hline Momoly: & 30 & 97800 & 0.1 & 591.5276 & $3.76-10.56$ & 69 & in \\
\hline
\end{tabular}

- Medium ail content, culvered in phonabioreocton

Spectral Analysis: ${ }^{14-15}$

\begin{tabular}{|l|l|l|l|}
\hline Functional group & Type of vibration & Characteristics Absorption $(\mathbf{C m}-\mathbf{1})$ & Intensity \\
\hline C-O (Ether) & Stretch & 1248.30 & Strong \\
\hline -C-H (Alkane) & Bending & 1359.62 & Variable \\
\hline C=C (Aromatic) & Stretch & 1546.55 & Medium-weak, multiple bands. \\
\hline C-H (Alkane) & Stretch & 2926.09 & Strong \\
\hline =C-H (Alkene) & Stretch & 3080.32 & medium \\
\hline O-H (Alcohol) & Stretch (H-bonded) & 3458.44 & Strong, broad \\
\hline Alkene & Stretch & 1644.28 & Variable \\
\hline
\end{tabular}


The result of fresh biofuel sample indicates that $(\mathrm{C}-\mathrm{H})$ Alkane stretching at $2926.09 \mathrm{~cm}^{-1}$ and intense broad peak and axial at $3000 \mathrm{~cm}^{-1}$. While alkane bending at $1359.2 \mathrm{~cm}^{-1}$ occur and the peak intensity is variable. The strong intensity due to stretching vibration of ether appears at $1248.30 \mathrm{~cm}^{-1}$. The $(\mathrm{O}-\mathrm{H})$ is also a weak broad peak is due to the presence of water content in bio-oil or may be due to alcohol which appears at $3458.44 \mathrm{~cm}^{-1}$. The aromatic $\mathrm{C}=\mathrm{C}$ stretching at $1546.55 \mathrm{~cm}^{-1}$ which intensity is medium weak multiple band The alkene $=\mathrm{C}-\mathrm{H}$ stretching at 3080.32 $\mathrm{cm}^{-1}$ which intensity is medium while the alkenes stretching occur at $1645.28 \mathrm{~cm}^{-1}$ and the intensity of peak is variable. It was concluded that the presence of different functional group of compounds indicate the presence of hydrocarbons in the fuel and also the $(\mathrm{O}-\mathrm{H})$ broad peak indicate the presence of water contents in bio-fuel. The broad O-H peak was due to the interaction (hydrogen bonding) among the water contents. This oil sample consist of Alkane, Alkenes, ether, alcohol, aromatic, the presence of this functional group indicate the presence of hydrocarbons in the bio-fuel.

\section{Biodiesel analysis:-}

The quality of biodiesel was assessed by measuring its properties such as flash point, viscosity, density, fire point and cloud point, as shown in Table 2. The higher flash point of biodiesel as compared to petro diesel makes it safer. Furthermore the higher cetane number of biodiesel make at anexcellent alternative fuel. The other properties of biodiesel are also very close to petro diesel.

\begin{tabular}{|l|l|l|l|}
\hline Properties & $\begin{array}{l}\text { Petro Diesel } \\
\text { (Lapuertaet al. 2008) }\end{array}$ & $\begin{array}{l}\text { Standard Diesel } \\
\text { (Lapuertaet al. 2008) }\end{array}$ & $\begin{array}{l}\text { Produced } \\
\text { Biodiesel }\end{array}$ \\
\hline Kinematic viscosity $\left(\mathrm{mm}^{2} / \mathrm{s}\right)$ & $1.3-4.1$ & $4-6$ & 4.7 \\
\hline Density $(\mathrm{kg} / \mathrm{m} 3)$ & 861 & 870.3 & 878.2 \\
\hline Flash point $\left({ }^{\circ} \mathrm{C}\right)$ & $60-80$ & $100-170$ & 140 \\
\hline Fire point $\left({ }^{\circ} \mathrm{C}\right)$ & $68-82$ & $120-180$ & 160 \\
\hline Cloud point $\left({ }^{\circ} \mathrm{C}\right)$ & $-15-5$ & $-3-12$ & 5 \\
\hline
\end{tabular}

\section{Conclusion:-}

The main objective of this project was to prove that with the help of micro algae specie Cladophoragoensis production of biodiesel is possible which may replace diesel in future.

Algae specie (Cladopharogeonsis) was successfully used as a raw material for biodiesel production. The process involved two steps e.g. oil extraction and transesterification. It was noted that the maximum amount of oil was extracted from algal biomass using combination of n-hexane and Di-ethyl Ether. Also higher algal to solvent ratio, smaller biomass size and longer contact time enhanced the yield of extracted oil. The maximum extracted oil was $70-80 \%$ fraction of biomass. For transesterification, the variables affecting the process were oil to methanol ratio, amount of catalyst, reaction time and temperature. It was noted that the maximum yield $>85 \%$ was achieved at a temperature of 105 degree Celsius.

\section{Future Aspects:-}

We believe that fuel production from algae can be cost competitive and widely scalable and deployable in the next 7-10 years. Although, conventional solvent extraction processes are inexpensive and easy to execute but the solvents used are toxic, consumes large volume of solvent and time and comprise more downstream processing (DSP) steps. The proposed process intensification techniques coupled with green solvents facilitates an eco-friendly process with high lipid quality in fewer DSP steps. The green solvents are recyclable and work as a single solvent system avoiding the solvent re-clamation task that usually takes place in conventional process. The high cost of green solvents can be easily compensated in terms of DSP steps minimization, energy reduction and saving time with less or no by-products. Process intensification techniques have the ability to extract lipid from wet biomass instead of drying the biomass as in conventional process. Similarly, transesterification is capable of transesterifying the lipids directly surpassing lipid extraction process. More effective options are the combinative methods where it aims for quality lipid extraction and biorefinery. For example, apart from biodiesel production, integration of several processes that include bioethanol production from de-fatted biomass and pigments, proteins extractions could help to make the process more economical. Moreover, as microalgae can grow in brackish /waste /fresh /marine water, to reduce the cost further, waste water could be utilized. 


\section{Acknowlegment:-}

The authors would like to thank BharatiVidyapeeth college of Engineering for encouragement and support. We would like to thank Dept of chemistry, Mumbai University for result analysis.

\section{Reference:-}

1. Felix Bast, Aijaz Ahmad John and SatejBhushan ,Indian Journal of Geo-Marine Sciences June, 2014

2. Balat, M., Balat, H. Progress in biodiesel processing. Appl. Energ., 2010; 87: 1815-1835.

3. Du, W., Li, W., Sun, T., Chen, X., Liu, D. Perspectives for biotechnological production of biodiesel and impacts. Appl. MicroboilBiot., 2008; 79: 331-337.

4. Lee, D.H., Algal biodiesel economy and competition among bio-fuels. Bioresource Technol., 2011;102: 43-49.

5. Chisti, Y. Biodiesel from microalgae. Biotechnology Adv., 2007;25: 249-306.

6. Rawat,I., Kumar, R. R., Mutanda,T. and Bux,F. Biodiesel from microalgae: A critical evaluation from laboratory to large scale production. Appl.Energ., 2013;103,:444-467.

7. Ihsanullah1, Sumaira Shah, Muhammad Ayaz,Iftikhar Ahmed, Murad Ali, Naveed Ahmad and Irshad Ahmad5Journal of Pure and Applied Microbiology · March 2015

8. Bast, F., John, A.A. \&Bhushan, S. (2105). Cladophoragoensis sp. nov. (Cladophorales, Ulvophyceae) - a bloom forming marine algae from Goa, India. Indian Journal of Geo-Marine Sciences44(12): 1874-1879.

9. Meng, X., Yang, J., Xu, X., Zhang, L., Nie, Q.,Xian, M. Biodiesel production from oleaginousmicroorganisms. Renew. Energ. 2009; 34: 1-5.

10. Lapuerta, M., Armas, O., Fernández, J.R. Effect of biodiesel fuels on diesel engine emissions. Prog. Energ. Combust., 2008;34: 198-223.

11. Georgogianni, K. G., Kontominas, M. G., Tegou, E., Avlonitis, D., Gergis,V. Biodiesel Production: Reaction and Process Parameters of Alkali- Catalyzed Transesterification of Waste Frying Oils. Energy \& Fuels 2007; 21: 3023-3027

12. Khan, N.A., Dessouky, E.H. Prospect of biodiesel in Pakistan. Renew. Sust. Energ. Rev., 2009; 13: 1576-1583.

13. Srivastava, A., Prasad, R. Triglycerides-based diesel fuels. Renew. Sust. Energ. Rev., 2000; 4: 111-133.

14. Zeban Shah1, Renato Cataluña Veses, Inamullah, Rosangela da silva,International Journal of Environmental \& Agriculture Research (IJOEAR) (2)2, 2016,pp 134-141.

15. Alica B., Lenka B., Kristína G. Research Papers Faculty Of Materials Science And Technology In Trnava Slovak University Of Technology In Bratislava (23), 36,2015,pp97-102. 